ISSN: 0213-1854

\title{
Las máscaras de Juan Rulfo. Revisión de dos cuentos de El llano en llamas
}

\author{
(Masks of Juan Rulfo. A review of two \\ tales from El llano en llamas)
}

\author{
GRACIA TEROL PLÁ \\ graciaterol@hotmail.es \\ Universidad de Almería
}

Fecha de recepción: 28 de junio de 2017

Fecha de aceptación: 30 de septiembre de 2017

Resumen: El trabajo contiene una revisión de dos cuentos de El llano en llamas, "En la madrugada" y "Es que somos muy pobres" que consta de una parte analítica basada en la comparación de las técnicas narrativas más destacables de los cuentos; y otra interpretativa que trata el sentido de las dos historias centrándose en motivos determinados como la violencia, la muerte o la figura de la mujer mexicana. Con ello, este artículo aspira a reafirmar el talento de Rulfo para manejar diversas estructuras y técnicas narrativas y para retomar los mismos ejes temáticos bajo la forma de distintas historias. A su vez, pretende ofrecer una interpretación de los cuentos centrada en los motivos mencionados.

Palabras clave: Juan Rulfo. El llano en llamas. Técnicas narrativas. Temas. Violencia. Muerte. Mujer mexicana.

\begin{abstract}
This work contains a review of two tales from El llano en llamas, "En la madrugada" y "Es que somos muy pobres". The review is made up of an analytic part based on the comparation of remarkable narrative techniques; and an interpretative part about the sense of both stories focused on determined themes like violence, death or the representation of the mexican women. According to this, the article aims to emphasises Rulfo's talent to manage a variety of structures and narrative techniques and to use the same themes in different plots. In addition, the work offers an interpretation of both tales centred in the themes mentioned.
\end{abstract}

Keywords: Juan Rulfo. El llano en llamas. Narrative techniques. Topics. 


\section{Gracia Terol Plá}

Violence. Death. Mexican woman.

\section{Introducción}

La obra literaria de Juan Rulfo ha sido examinada desde distintas perspectivas dando lugar a trabajos que tratan aspectos como el empleo del silencio (Villoro, 2009; Gómez López-Quiñones, 2013), el recurso del sentido del humor (Garrido, 2003), el uso de figuras literarias (Mansour, 2003). Igualmente, encontramos interesantes aportaciones sobre los temas recurrentes y estrategias narrativas del autor ${ }^{1}$ o sobre la relación de Rulfo con el Realismo Mágico $^{2}$ y con la tradición grecolatina ${ }^{3}$. Si bien la mayor parte de la bibliografía se ocupa de Pedro Páramo, existen valiosos estudios centrados en El llano en llamas $(1953)^{4}$ que interpretan los cuentos, no exclusivamente como el "paso previo" a la novela ${ }^{5}$, sino atendiendo al valor que tienen en sí mismos y a la información que ofrecen sobre el contexto y las estrategias narrativas del autor.

El talento de Rulfo a la hora de elaborar estructuras narrativas complejas y de recurrir a los mismos núcleos temáticos ya se manifestaba en los cuentos debido, en gran parte, a la variedad técnica, estructural y argumental que presenta El llano en llamas, frente a la novela, que consta de un único argumento y estructura. En base a lo anterior, nos proponemos comparar dos cuentos para constatar la habilidad del autor al manejar una gran variedad de estructuras y técnicas narrativas y de presentar temas semejantes a través de distintas historias.

Para ello, el trabajo se centra en los cuentos, "En la madrugada" y "Es que somos muy pobres", dos casos que muestran características narrativas y estructurales bastante dispares e interesantes coincidencias temáticas. Tras presentar al autor y su obra y describir los argumentos de los dos cuentos, se estudian las técnicas narrativas en un epígrafe analítico que trata de exponer las diferencias entre las historias. En un apartado posterior, ofrecemos una interpretación de los cuentos que atiende sobre todo al tratamiento de la

\footnotetext{
${ }^{1}$ Temas como la violencia (Portal, 1990) o la marginalidad (De la Fuente, 1996)

2 González Boixo (2015) señala que el tratamiento de lo fantástico como hecho inusual en la obra rulfiana, impide que se hable de Realismo Mágico.

${ }^{3}$ Existe una interpretación mítica de Pedro Páramo (defendida por Carlos Fuentes, 2003) a la que ciertos autores (Monsiváis, 2003; Roa Bastos, 2003; Mansour, 2003) se oponen alegando, en algunos casos, que sería más coherente vincular la obra con la tradición mexicana.

${ }^{4}$ Mencionamos los trabajos de Blanco Aguinaga (2003), Rodríguez-Alcalá (1967), Poot (2003) o Durán (2003), entre otros.

5 "Todos los rasgos esenciales de la visión del mundo y del estilo de los cuentos de Rulfo reaparecen en Pedro Páramo" (Blanco Aguinaga, 1988: 29)
} 
Las máscaras de Juan Rulfo. Revisión de dos cuentos de El llano en llamas

violencia y la muerte y a la representación de la figura de la mujer ${ }^{6}$.

Más que enmarcarnos en una teoría crítica determinada, seguimos el planteamiento utilizado por González Boixo (1983: 74), el cual estudia el relato diferenciando dos lecturas: una analiza la anécdota, la historia; y otra interpreta, busca unidades de sentido y hace referencia a lo que la historia simboliza. En este caso, se ha hecho mayor hincapié en la lectura interpretativa, pues, dada la cantidad de análisis que ha suscitado la obra de Rulfo, resultaba complicado añadir algo nuevo al nivel analítico. En el epígrafe interpretativo nos apoyamos en las teorías de Portal (1990) sobre el planteamiento de la violencia en Rulfo y en la obra de Estrada Cárdenas (2005) en lo referente a la representación de la mujer. Para entender este tratamiento de la violencia y la mujer de forma contextualizada, se recurre a las reflexiones de Octavio Paz (1995) sobre el ser mexicano y su tradición.

En definitiva, el propósito de este trabajo es destacar la habilidad de Rulfo para elaborar una gran variedad de estructuras y repetir temas tratados de forma distinta en diferentes historias y, a su vez, ofrecer una interpretación de los cuentos centrada en los temas citados.

\section{El autor y su obra}

\subsection{Juan Rulfo}

En 1953 el mexicano Juan Rulfo, quien había sido hasta entonces un oficinista introvertido sin más relación con el mundo literario que una beca en el Centro Mexicano de Escritores y una gran pasión lectora, sorprendió al público y la crítica con la publicación de una recopilación de cuentos titulada El llano en llamas. Con una calidad inusual para tratarse del estreno de un principiante, la obra reveló el talento de Rulfo, lo situó en el panorama literario mexicano (situación que sería reafirmada por su novela más adelante) y contribuyó a crear las múltiples leyendas que giran en torno a su persona ${ }^{7}$, las cuales hacen referencia a su reducida producción literaria, al rápido reconocimiento que obtuvo, a su silencio prematuro e inquebrantable...

Refuerza esta aura enigmática el carácter taciturno y reservado del autor, fruto de su propia naturaleza, pero también de las experiencias traumáticas de

\footnotetext{
${ }^{6}$ Aunque estos temas se repiten con frecuencia en su obra, en los cuentos escogidos se manifiestan de manera bastante clara, motivo por el cual, en parte, los elegimos.

${ }^{7}$ Una de ellas se refiere a la imagen de "escritor casual" que el propio Rulfo ayudó a difundir diciendo que se consideraba un "simple aficionado" y que los cuentos "se los susurraba su tío Celerino" (por ello, cuando los susurros cesaron, tuvo que dejar de publicar). "La excusa del tío Celerino es de las más originales que conozco de entre todas las que han creado los escritores del No para justificar su abandono de la literatura" (Vila-Matas, 2000: 17)
} 


\section{Gracia Terol Plá}

su infancia. Nacido en 1918 en el estado de Jalisco ${ }^{8}$, la niñez de Rulfo ocupa la última etapa de la Revolución Mexicana (1910-1920) y la Rebelión de los Cristeros (1926-1928)9, siendo este último el conflicto que marcaría el resto de su vida. La Rebelión trajo la ruina familiar y la muerte de casi todos sus parientes y causó que el joven Rulfo terminara en un lúgubre orfanato donde aprendería a deprimirse y a sumergirse en la soledad (Soler Serrano, 1977).

En la década de los treinta Juan Rulfo se trasladó a México, donde desempeñó una serie de trabajos variados. Lo más destacable de esta etapa es su asistencia a algunos cursos de literatura en la Facultad de Filosofía y Letras y el hecho de que, en medio de una ciudad extraña, Rulfo combate la soledad escribiendo en sus ratos libres. De esta costumbre surgiría una novela, El bijo del desconsuelo, con un argumento semejante a la realidad de su autor, quien terminó destruyéndola consciente de los defectos que presentaba. Aunque el segundo intento ("La vida es muy seria en sus cosas" de 1945) no obtuvo mayor éxito que el anterior, el espíritu perfeccionista de Rulfo le llevó a superarse con otros dos cuentos, "Nos han dado la tierra" y "Macario", que aparecieron ese mismo año y fueron alabados por la crítica (González Boixo, 1983: 14-15).

El Rulfo escritor revelaba su talento a través de una serie de historias que serían finalmente recogidas en El llano en llamas (1953). Ya por aquellos años tenía mentalmente esbozada su primera (y, a la vez, última) novela, Pedro Páramo, que fue publicada en 1955 y provocó reacciones diversas entre el público y la crítica. "Si bien los cuentos habían sido considerados prácticamente magistrales, la novela traerá desconciertos" (Ruffinelli, 2003: 305). Esta reacción se debía a que, aunque la obra planteaba temas utilizados en la novela realista de la Revolución, lo hacía de un modo distinto y sorprendente, dejando atrás la tendencia regionalista para dar a las situaciones y temas un sentido más universal. Rulfo había procedido a la "a la mitificación de personajes y conductas" (Portal, 1984: 21) superando la tradición de un género con una gran obra que parecía ponerle punto y final ${ }^{10}$.

Pese a que se necesitó cierto tiempo para comprender y valorar justamente la novela, ya en la década de los 60 los círculos literarios consideraban El llano en llamas y Pedro Páramo dos obras maestras de sus respectivos géneros. Lectores,

\footnotetext{
${ }^{8}$ No se sabe con seguridad el lugar de nacimiento de Rulfo. Él mismo, quizá por su personalidad difícil y reservada, daba indicaciones contradictorias en las entrevistas (Roffé, 2012: 19-33)

${ }_{9}$ Para más información sobre esta etapa histórica de México, véase El Espejo enterrado (1992) de Carlos Fuentes.

10 Aun así, hay que destacar que la temática reapareció en novelas posteriores, por ejemplo, en obras de Fuentes como La región más transparente o La muerte de Artemio Cruz, aunque ya presentaba un tratamiento distinto (Portal, 1984: 23-24)
} 
Las máscaras de Juan Rulfo. Revisión de dos cuentos de El llano en llamas

críticos y teóricos permanecieron desde entonces atentos a las novedades de Rulfo, a la espera de que este volviera a impactarlos con otro trabajo. Lo que no sospechaban es que la trayectoria literaria del autor ya había alcanzado su fin definitivo, terminando tan repentinamente como se inición ${ }^{11}$. Para ser justos, era difícil sospecharlo, ya que el escritor llegó a mencionar un proyecto en el que se hallaba inmerso, la escritura de una novela titulada La cordillera. Pero lo cierto es que ni esta, ni otras obras llegaron a ver la luz (Ruffinelli, 2003: 309)

Distintas teorías han intentado explicar su decisión de no volver a publicar.

\begin{abstract}
Muchas son las hipótesis sobre lo que podríamos llamar la agrafía de Juan Rulfo. Una es la que vincula el alcoholismo con su silencio editorial. Otra se reafirma en la idea de que dejó de publicar porque ya había dicho todo lo que tenía que decir y de forma insuperable en sus dos obras de ficción (...) Pero tengo para mí que la postergación y el abandono de Rulfo fueron productos de sus miedos, de sus propias imposibilidades... (Roffé, 2012: 231-232)
\end{abstract}

Puede que Rulfo, autor parco en palabras y maestro del silencio, tras intentos fallidos de encontrar la historia adecuada para continuar su trayectoria, se diera cuenta de que era precisamente el silencio la mejor continuación, la única reacción posible ante su novela. Sin embargo, a falta de más información, en este punto solo podemos conjeturar. Lo que resulta innegable es que Juan Rulfo, aun siendo autor de una escasa producción literaria, se había convertido en una figura fundamental de la narrativa hispanoamericana.

\title{
2.2. El llano en llamas
}

En el momento de su publicación, El llano en llamas, si bien consiguió buenas críticas y atrajo la atención de lectores y estudiosos, no supuso un gran éxito de ventas ni la obtención de la fama mundial inmediata por parte de su autor. Habría que esperar a los juicios que suscitó Pedro Páramo para que El llano en llamas empezara a ser releído por el público. A partir de aquí, los cuentos serán sometidos a un proceso de revisión que lleva al aumento de las ediciones de la obra y refuerza el reconocimiento de la misma (Blanco Aguinaga, 1988: 14-15).

El llano en llamas se compone de 17 relatos que no siguen un orden lógico aparente. A excepción de "Luvina", cuento de tintes fantásticos que ha sido considerado el germen de Pedro Páramo, encontramos historias de carácter

11 Aparte de la edición de El gallo de oro y otros textos para cine (1980), obra más vinculada a su faceta de guionista que a la de escritor, Rulfo permaneció en silencio (González Boixo, 1983: 12) 


\section{Gracia Terol Plá}

realista ubicadas en el México rural de los tiempos de la Revolución y posrevolución. No resulta complicado situar espacialmente los cuentos, ya que estos incluyen alusiones a localidades del estado de Jalisco, como Talpa o San Gabriel. A pesar de tratarse de lugares reales, en la obra son descritos como espacios grises y sofocantes con el fin de crear la atmósfera depresiva de los cuentos. La dimensión temporal presenta mayores complejidades, pues, en lugar de situar sus cuentos en un momento histórico determinado, Rulfo, a través de un ambiente evocador, trasciende el tiempo histórico para alcanzar un tiempo mítico y eterno. La Revolución actúa como "telón de fondo"12, pero el autor no la analiza, pues "el entorno le sirve, no para rendir testimonio, sino para construir un símbolo" (Villoro, 2009). Con este tiempo impreciso demuestra que las situaciones realistas de sus relatos no son un fin, sino el medio para expresar temas universales que afectan al hombre.

Los personajes son campesinos oprimidos, bandidos, revolucionarios... seres marginales que soportan pasivamente la hostilidad del medio y la fatalidad de su destino. Esto se manifiesta a través de monólogos o diálogos breves que reflejan el retraído carácter mexicano y en los que no faltan ráfagas de humor, frases ambiguas y silencios expresivos ${ }^{13}$. En este mundo árido regido por la soledad y la incomunicación, el narrador se dirige a un hipotético interlocutor del que nunca obtiene respuesta. El relato se convierte en monólogo ensimismado, un diálogo con la nada que cuenta una historia en la que apenas se da acción alguna. En ciertos casos, aunque se identifica una acción culminante (el asesinato de Don Lupe Terreros en “¡Diles que no me maten!”, de Anacleto Morones en el relato que lleva su nombre...), al inicio del cuento esta ya se ha producido, de modo que la narración se articula a modo de retrospección para rememorar los hechos más relevantes.

En otros, no hay acción como tal y la historia se centra en el estado triste y abrumador en el que se encuentran los personajes por su condición (como en "Macario") o por ser víctimas de un proceso que son incapaces de detener y que los sumirá en la desgracia (la crecida del río en "Es que somos muy pobres", la repartición de terrenos en "Nos han dado la tierra"...). En todos los casos, se emplea un tono objetivo que pone de relieve la impotencia de los personajes y su tragedia vital irresoluble. Sus desgracias son tratadas "sin exagerar, sin patetismo" ya que los personajes están "demasiado ocupados en sobrevivir, en luchar, defenderse o atacar, para poder sentir piedad,

12 Se detectan escasas referencias puntuales a momentos históricos en cuentos como "El llano en llamas", "La noche que lo dejaron solo" o "Paso del Norte".

${ }^{13}$ Los silencios se han interpretado de varias formas: como expiación de la culpa, evocación de mitos (Gómez López-Quiñones, 2013: 86-89), superación de lo nacional etc. 
remordimiento o melancolía" (Durán, 2003: 89-90). Los personajes aceptan con resignación la crudeza del mundo y se encierran en sí mismos percibiéndolo todo "por dentro y desde dentro", ofreciendo así la "monótona y difusa vivencia interior" que se detecta en los cuentos (Blanco Aguinaga, 1988: 19). Este enfoque subjetivo ${ }^{14}$ se combina con la objetividad mencionada, ya que el autor no se posiciona ni interpreta los acontecimientos a través del personaje ${ }^{15}$.

En definitiva, Rulfo nos transporta a un mundo desolador en el que la muerte está a la orden del día y los personajes o bien se muestran impotentes o bien luchan pero fracasan repetidamente hasta caer en la desilusión. En este ambiente, la soledad y la incomunicación (fruto del carácter del mexicano ${ }^{16} \mathrm{O}$ del abandono del entorno rural por parte del gobierno ${ }^{17}$ ), el sentimiento de orfandad (que puede referirse a una sensación de desarraigo ${ }^{18} \mathrm{o}$ a una situación de orfandad real, consecuencia de los crímenes de la Revolución ${ }^{19}$ ), la pasividad del campesinado y los estallidos de violencia son algunos de los motivos esenciales de los cuentos que el autor retomará en Pedro Páramo.

\section{3. "En la madrugada" y "Es que somos muy pobres"}

El trabajo estudia dos cuentos: "En la madrugada" y "Es que somos muy pobres". El primero narra un crimen y sus consecuencias a lo largo de ocho fragmentos. Tras describir el ambiente inquietante del pueblo, se presenta al viejo Esteban, un vaquero al servicio de don Justo Bambrila, y se exponen sus recuerdos sobre el día del crimen. El viejo Esteban recuerda haberse ensañado con un becerro del patrón y haber sido sorprendido por don Justo. El patrón, furioso, lo golpea hasta dejarlo inconsciente. Al recobrar el sentido, Esteban se entera de que su jefe ha muerto misteriosamente y se le acusa a él del asesinato. Lo insólito es que el personaje, aunque se defiende afirmando no recordar nada de lo sucedido, llega a plantearse si de verdad no es él el culpable.

El cuento retrocede para ofrecernos cómo fueron percibidos los mismos

14 Tal y como afirma Villoro (2009), "en la obra de Rulfo todo depende de la subjetividad, ya que cada dato, cada percepción está filtrada por la conciencia”.

${ }^{15}$ Este equilibrio explica que la obra haya sido valorada como "visión personal del mundo y, a la vez, visión profunda de la realidad mexicana en su Historia" (Blanco Aguinaga, 1988: 17)

${ }^{16}$ Según Octavio Paz, "somos de verdad distintos. Y, de verdad, estamos solos" (Paz, 1995: 154).

17 Tema que se refleja en "Luvina" y en "Nos han dado la tierra".

${ }^{18} \mathrm{El}$ sentimiento de orfandad es "el fondo constante de nuestras tentativas políticas y de nuestros conflictos íntimos. México está tan solo como cada uno de sus hijos” (Paz, 1995: 226)

${ }^{19}$ La Revolución, generadora de violencia y causa de desencanto, es un tema recurrente del autor y le sirve para presentar al campesino que, defraudado por los ideales revolucionarios, ya no encuentra nada externo a lo que agarrarse. 


\section{Gracia Terol Plá}

hechos por don Justo y proporcionarnos más información sobre él, como la relación incestuosa con su sobrina. Desde la perspectiva del patrón, la escena de la paliza se repite con ambigüedad y esta vez tampoco queda claro si se trata de un crimen o quién lo ha cometido. Finalmente, sabemos que Esteban está preso a la espera de un juicio, todavía dudando sobre su inocencia y restándole importancia al asunto.

"Es que somos muy pobres" narra las desgracias de una familia de campesinos. Todo empieza con la muerte de la tía, suceso del que pronto se repone la familia, y continúa con el aguacero que arruina la cebada, un grave contratiempo para su subsistencia. En este punto aparece la amenaza principal, la crecida del río, que termina arrasando todo a su paso. Pronto el narrador descubre que la riada se ha llevado a la vaca de su hermana Tacha, la cual constituía la dote que iba a permitirle casarse. La catástrofe aumenta al conocer casos anteriores de la familia: otras dos hermanas, holgazanas y desobedientes, fueron expulsadas de la casa paterna y acabaron prostituyéndose.

El padre se mortifica al presentir que Tacha correrá la misma suerte que sus hermanas y la angustiada madre cree que la situación se debe a la "maldad" de unas hijas enviadas por Dios como castigo por algún pecado olvidado. La única esperanza la encarna el becerro que acompañaba a la vaca, cuya muerte aún no se ha confirmado. Sin embargo, su supervivencia es percibida por los lectores como una ilusión vana. Por eso, Tacha llora en silencio mientras crece más y más, precipitándose, sin remedio, hacia su propia e irremediable tragedia.

\section{Análisis de técnicas narrativas ${ }^{20}$}

Las ocho partes de "En la madrugada" forman una estructura circular pues, como indica Rodríguez-Alcalá (1967: 499), el primero y el último fragmento enmarcan el relato ${ }^{21}$. El primero presenta, a través de un narrador externo en tercera persona, el ambiente difuso que envuelve el cuento. El tono objetivo e impersonal y el empleo del tiempo presente crean cierta impresión de intemporalidad, la sensación de que el fragmento bien podría reflejar cualquier

${ }^{20} \mathrm{Al}$ analizar las técnicas narrativas de los cuentos, nos centramos en el tratamiento del narrador, la estructura y el tiempo. Ciertos rasgos, como el espacio o los personajes, no se incluyen en este análisis debido a que coinciden, en gran medida, con las características típicas de la obra de Rulfo ya descritas. En lugar de realizar un análisis exhaustivo, atenderemos fundamentalmente a las técnicas que nos permitan establecer diferencias entre los dos cuentos. En lo que respecta al tiempo en los cuentos, procuraremos no repetir ideas que ya se hayan expuesto (técnicas para difuminar el tiempo histórico, ruptura del tiempo lineal...).

${ }^{21}$ Mientras que el primer fragmento expone en presente la movilización de un escenario en el que la naturaleza es la protagonista, el último habla en pretérito imperfecto de una anécdota que ya forma parte del pasado y presta mayor atención a los elementos humanos (Portal, 1984: 185-190) 
Las máscaras de Juan Rulfo. Revisión de dos cuentos de El llano en llamas

amanecer en San Gabriel. No obstante, la mención de la mancha ${ }^{22}$ que se cierne sobre el pueblo (símbolo que adelanta lo que va a suceder) nos permite deducir que la descripción corresponde a la madrugada del crimen.

En la segunda parte aparece Esteban declarando su intención de desahijar a la vaca, anunciando así el hecho que provocará el incidente. La tercera combina el soliloquio del personaje, en el que trata de recordar lo acontecido, con el maltrato del becerro contado por un narrador en tercera persona. La siguiente parte la ocupa por entero el testimonio de Esteban, quien expone su versión de los hechos y su estado de preso y amnésico. En el quinto fragmento volvemos a encontrar un narrador externo en tercera persona que refleja las tropelías de don Justo y repite la pelea entre él y su empleado. A continuación, exponemos los dos fragmentos que reproducen esta escena, primero desde la perspectiva del vaquero y después desde la de un narrador externo (Rulfo, 1988: 72-74):

Y le hubiera roto el hocico si no hubiera surgido por allí el patrón don Justo, que me dio de patadas a mí para que me calmara. Me zurró una sarta de porrazos que hasta me quedé dormido entre las piedras, con los huesos tronándome de tan zafados que los tenía. Me acuerdo que duré todo ese día entelerido y sin poder moverme por la hinchazón que me resultó después y por el mucho dolor que todavía me dura. ¿Qué pasó luego? Yo no lo supe. No volví a trabajar con él. Ni yo ni nadie porque ese mismo día se murió.

Eran las seis de la mañana. Se dirigió al corral para abrirle el zaguán al viejo Esteban (...) En eso iba pensando cuando se encontró al viejo Esteban peleándose con el becerro, metiendo sus manos como de alambre en el hocico del animal y dándole de patadas en la cabeza (...) Corrió y agarró al viejo por el cuello y lo tiró contra las piedras, dándole de puntapiés y gritándole cosas de las que él nunca conoció su alcance. Después sintió que se le nublaba la cabeza y caía rebotando contra el empedrado del corral. Quiso levantarse y volvió a caer, y al tercer intento se quedó quieto. Una nublazón negra le cubrió la mirada cuando quiso abrir los ojos.

22 "Entonces una mancha como de tierra envolvió al pueblo, que siguió roncando un poco más, adormecido en el calor del amanecer" (Rulfo, 1988: 70) 


\section{Gracia Terol Plá}

La decisión de narrar la misma escena dos veces, una desde el punto de vista subjetivo de Esteban y otra desde la neutralidad de un narrador omnisciente, tiene que ver con el equilibrio entre subjetividad y objetividad que el autor pone en práctica. Igualmente, influye el hecho de que Rulfo poseyera ciertas dotes para el mundo del cine ${ }^{23}$. La concepción del cuento en fragmentos que mezclan narradores, perspectivas y cronologías que el lector debe reordenar e interpretar se acerca a la construcción de un guion y al montaje cinematográfico. Mas, pese a que la pelea se presenta desde dos perspectivas, no se aclara nada. Es posible que esta técnica narrativa buscara excitar y confundir al lector ${ }^{24}$ relatando la muerte ambigua del patrón (a quien se le nubló la mente) sin esclarecer por qué se produce y, sospechosamente, sin mencionar cuál fue la reacción del vaquero ante la paliza ${ }^{25}$ (Rodríguez-Alcalá, 1967: 506-507).

Esteban completa su monólogo desde la cárcel en el séptimo fragmento con una descripción del mal genio de su patrón mostrando una actitud tranquila ante la posible muerte. Habla en presente, dando a entender que el relato se ha producido desde el abora de la cárcel ${ }^{26}$. En el fragmento final, el entierro del patrón, la mancha continúa cubriendo al pueblo e indica que el crimen se ha perpetrado. La niebla que al inicio se alzara vuelve a extenderse sobre el lugar como un telón simbólico que se abre al inicio de la historia y cae cuando esta termina. La frase final ("Y las campanas estuvieron doblando a muerto toda la noche, hasta el amanecer, hasta que fueron cortadas por el toque del alba", Rulfo, 1988: 75) confirma la estructura circular, ya que Rulfo deja la historia prácticamente donde la empezó: al alba. Así, el cuento, acentuando la sensación de imprecisión y vaguedad, como si nada de todo aquello hubiera ocurrido realmente, comienza y termina "en la madrugada".

"Es que somos muy pobres" presenta una estructura no fragmentaria y un único narrador interno que cuenta los hechos en primera persona. Aunque no se especifica en el relato, ciertos detalles, que denotan una ternura e ingenuidad inusuales en los personajes rulfianos, nos llevan a creer que el narrador es un niño pequeño, el hermano menor de Tacha. Un indicio sería el intento inocente por consolar a la niña con un abrazo o la empatía que muestra hacia la vaca

23 Para más información sobre la faceta cinematográfica de Rulfo véase Gordon (2003: 346-347).

${ }^{24}$ Rodríguez-Alcalá (1967: 499) afirma que Rulfo también juega con el tiempo para confundir al lector y hacerle creer que todo ha sucedido en el mismo día, cuando realmente no ha sido así.

25 Además de la escena de la pelea, se detectan otras repeticiones que también estarían relacionadas con los factores y motivos explicados. Algunas de ellas son la descripción del pueblo, el soliloquio de Esteban desde la cárcel, la aparición del patrón con su sobrina... (Rodríguez-Alcalá, 1967: 505)

26 A excepción de la primera, segunda y sexta parte, las demás aparecen en pretérito imperfecto porque narran hechos que ya han sucedido. 
Las máscaras de Juan Rulfo. Revisión de dos cuentos de El llano en llamas

desaparecida (que le hará apiadarse del animal antes que preocuparse por la economía familiar).

Si bien al principio el narrador va marcando la cronología de la historia ("la semana pasada se murió...", "el sábado, cuando ya la habíamos enterrado..." Rulfo, 1988: 55), esto no significa que el argumento se desarrolle linealmente. Tal y como sucedía en el relato anterior, el hermano nos habla desde un momento en el presente (en el que se encuentra consolando a Tacha) y narra de forma retrospectiva, como se aprecia en el fragmento final del relato: "Y Tacha llora al sentir que su vaca no volverá porque se la ha matado el río. Está aquí, a mi lado, con su vestido color de rosa, mirando el río desde la barranca (...) Yo la abrazo tratando de consolarla, pero ella no entiende" (Rulfo, 1988: 59).

La narración del hermano se remonta a la semana anterior y, a partir de ahí, sigue una progresión lineal que se ve interrumpida por una prolepsis ${ }^{27}$ que anticipa la tragedia central: "La semana pasada se murió mi tía Jacinta, y el sábado, cuando ya la habíamos enterrado y comenzaba a bajársenos la tristeza, comenzó a llover como nunca (...) Y apenas ayer (...) supimos que la vaca que mi papá le regaló el día de su santo se la había llevado el río" (Rulfo, 1988: 55). Tras esa breve anticipación, el narrador retoma el hilo de su historia por donde lo dejó, en el momento en que aún no se conocía la noticia del animal perdido: "El río comenzó a crecer hace tres noches..." (Rulfo, 1988: 55).

La historia prosigue y el narrador explica cómo, de un día para otro, el río se desbordó arrastrando consigo árboles, casas y animales. Es entonces cuando se entera de la pérdida de la vaca Serpentina y, como cada vez que surge en el relato esta catástrofe central, se detiene el tiempo de la narración. Si antes la pausa narrativa introducía una prolepsis, ahora da pie a una digresión reflexiva ${ }^{28}$ en la que el narrador imagina la escena trágica y patética de la muerte de la vaca (Rulfo, 1988: 56-57):

Por eso nos subimos por la barranca, donde también hay gente mirando el río y contando los perjuicios que ha hecho. Allí fue donde supimos que el río se había llevado a la Serpentina (...) No acabo de saber por qué se le ocurriría a la Serpentina pasar el río este (...) Y aquí ha de haber sucedido eso de que se murió. Tal vez se le ocurrió despertar al sentir que el agua pesada le golpeaba las

27 Se hace referencia a una prospección, un avance temporal o flash-forward (Valles Calatrava y Álamo Felices, 2000: 89)

28 Se trata de una pausa narrativa o detención temporal (Valles Calatrava y Álamo Felices, 2000:

89) en la que el personaje expone sus pensamientos. 
Gracia TEROL Plá

costillas. Tal vez entonces se asustó y trató de regresar; pero al volverse se encontró entreverada y acalambrada entre aquella agua negra y dura como tierra corrediza. Tal vez bramó pidiendo que le ayudaran. Bramó como sólo Dios sabe cómo.

Tras esta, se retoma el hilo narrativo y los personajes se preguntan por la suerte del becerro. De nuevo, la mención de la pérdida de la vaca provoca una pausa en la que se rememora la historia de las hermanas. Sigue la narración con la preocupación por el matrimonio de la hermana y por la suerte del becerro. "Ojalá no se le haya ocurrido pasar el río detrás de su madre" (Rulfo, 1988: 58). Una vez más, la mención de la tragedia principal desemboca en una nueva pausa narrativa que introduce una digresión sobre la mortificación de los padres. Finalmente, concluye esa última pausa y se retorna al relato principal, esta vez en presente: "Y Tacha llora al sentir que su vaca no volverá porque se la ha matado el río" (Rulfo, 1988: 59).

No es difícil detectar distinciones entre la forma y las técnicas narrativas de ambos cuentos. Frente a una estructura circular y fragmentaria que presenta varios narradores (tanto externos como internos), tenemos otra no fragmentaria y lineal que ocupa un único narrador interno. La narración en "Es que somos muy pobres" se ve constantemente interrumpida por saltos cronológicos y digresiones que ofrecen matices y enriquecen la historia. Más, si aquí las interrupciones del hilo narrativo se integran en el discurso de un narrador único, en "En la madrugada" los saltos cronológicos suponen un cambio de narrador y, a menudo, el inicio de un nuevo fragmento. En este último caso, se presenta un hecho desde diversos puntos de vista, a diferencia del otro, en que todo es "filtrado" subjetivamente por el personaje que narra. Por último, pese a que en ambos cuentos se deja un final abierto, "En la madrugada" gira en torno a una acción (el asesinato del patrón) y plantea un misterio sin resolver, mientras que en "Es que somos muy pobres" no es posible identificar una acción concreta y todo el relato se centra en describir el estado de la pobreza. Se podría afirmar que estas diferencias ponen de relieve la variedad de recursos y el manejo de técnicas narrativas que utiliza Juan Rulfo.

\section{Interpretación}

\subsection{La violencia retardada}

"En la madrugada" demuestra que Juan Rulfo aprendió y ejecutó con eficacia una de las técnicas más características de la narrativa moderna: la creación de misterio en el cuento (Doñán, 2003: 366). El ambiguo final del relato despertó la curiosidad de distintos autores que proponían soluciones para 
Las máscaras de Juan Rulfo. Revisión de dos cuentos de El llano en llamas

esclarecer el argumento. Rodríguez-Alcalá (1967: 506) plantea la opción de que el viejo campesino fingiera su amnesia, a modo de astuta estrategia para no afrontar su culpa. Por añadidura, no rechaza totalmente la posibilidad de que el culpable sea un tercer personaje al que no llegamos a percibir, aunque reconoce que esta versión puede ser fruto de un exceso de imaginación (RodríguezAlcalá, 1967: 507). Portal (1984: 191) cree que "más que la historia de un crimen, es la historia de un accidente" dada la falta de elementos que desencadenan la acción.

En nuestro caso, descartamos la solución del tercer personaje desconocido por parecer un deus ex machina ${ }^{29}$ más propio de un thriller que de la obra de Rulfo y por considerar que desentona con este mundo literario repetitivo y hermético. Tampoco coincidimos con la propuesta de la amnesia fingida por dos razones principales. Por un lado, el uso de la amnesia como truco para librarse de la muerte lleva a pensar que el viejo no se adecúa a las características generales de los personajes de Rulfo. Como vimos, se trata de campesinos que aceptan su suerte sin tratar de mejorar sus condiciones. Incluso aquellos personajes astutos y rebeldes que pretenden burlar al destino pronto ven sus intentos frustrados y terminan aceptando su condición: el revolucionario de "El llano en llamas", tras desafiar al gobierno y mentir para que no lo vinculen a la Revolución, sale de la cárcel y acepta pasivamente su nuevo rol de padre ${ }^{30}$. Por ello, defendemos que un personaje que ideara artimañas para despistar al lector y esquivar las consecuencias de su suerte supondría un caso atípico.

Por otro lado, dada la tendencia a la simbolización del autor, la amnesia podría ser un reflejo de la actitud del mexicano ante la muerte. Razona el personaje que si hubiera matado a alguien tendría que acordarse porque matar es un asunto serio, y más aún si se mata a un superior. A pesar de todo, no logra recordar nada. Tal vez debido a que la muerte no sea percibida como un asunto tan serio, a fin de cuentas, y aparezca en la obra como "algo trivial que se nos ofrece sin gran comentario" (Durán, 2003: 105). A juzgar por el testimonio del vaquero, se diría que la muerte del patrón, las pérdidas de memoria y el destino que le espera tienen para él la misma irrelevancia. Esto recuerda a las palabras de Octavio Paz (1995: 194) sobre la actitud del

${ }^{29}$ González Vázquez lo define como el recurso mediante el cual un dios (o, en este caso, un personaje ajeno a la historia) aparecía súbitamente al final de una trama para resolver los problemas pendientes (González Vázquez, 2014: 102)

30 Otro ejemplo lo constituye Lucas Lucatero. Este, tras inventar una estrategia para librarse de las mujeres y tratar de desmentir el mito de Anacleto Morones para sustituirlo en sus correrías, tendrá que aceptar que ni todas las mujeres son expulsadas, ni va a desaparecer la admiración que estas sienten por el "niño Anacleto" (Durán, 2003: 118) 


\section{Gracia Terol Plá}

mexicano: "nuestra indiferencia ante la muerte es la otra cara de nuestra indiferencia ante la vida". Es posible que dicha indiferencia se manifestara en el relato en forma de olvido, convirtiendo la amnesia en un símbolo más del universo rulfiano.

Partiendo de la idea de una amnesia no fingida y teniendo en cuenta el mundo gris y pesimista de Rulfo, deducimos dos versiones posibles: (1) la muerte se ha producido por un accidente o una causa ajena al vaquero y este termina injustamente encarcelado; (2) el vaquero ha matado al patrón en un arrebato para luego quedar amnésico.

En la primera versión podría parecer que la violencia juega un papel menor y que, al encarcelar a un inocente, se está narrando la historia de una injusticia. Este posible desenlace concordaría con la impotencia que el campesino muestra ante la "ley" y sus múltiples facetas (la ley religiosa que lleva a despreciar la dura vida terrenal, la ley social que encarnan las autoridades, la ley del medio hostil y de una vida en la que solo importa sobrevivir ${ }^{31} .$. ) ya que frente a ellas, el campesino siempre parece salir perdiendo. Aun así, esta versión decae a causa de la excesiva victimización del campesino y la concepción del crimen como un simple malentendido. Hay que valorar que, con crimen o sin él, la violencia está presente a lo largo del relato ${ }^{32}$ : el maltrato del becerro, el incesto, la paliza... De ahí que, aunque se tratara de un accidente, no estaríamos ante personajes completamente inocentes o condenas injustas. No debe olvidarse que "en este mundo todos son culpables" (Harss, 2003: 73).

La versión alternativa seguiría la línea establecida por los cuentos (pues en casi todos hay un asesinato) y reflejaría la indiferencia ante la muerte y la expresión de la violencia por parte del mexicano. El mexicano ha sido descrito como un ser retraído y permanentemente escondido tras una máscara ${ }^{33}$. Bajo esta, el campesino defraudado tras la Revolución, a menudo esconde un gran rencor que termina explotando en los momentos más inesperados. Como señala Octavio Paz, "si en la Fiesta, en la borrachera o la confidencia nos abrimos lo hacemos con tal violencia que nos desgarramos y acabamos por anularnos" (Paz, 1995: 200).

El caso del cuento podría responder a este esquema: el viejo campesino,

31 Planteamos la tercera faceta, mientras que las dos primeras ya habían sido descritas por Blanco Aguinaga (1988: 29-30)

32 Como señala Poot Herrera, aunque en cuatro cuentos no se produzca una muerte como tal, esta está presente siempre, de forma lateral y amenazante, pues "si no hubiera muerte no existiría El llano en llamas" (Poot Herrera, 2003: 398)

33 "El mexicano se me aparece como un ser que se encierra y se preserva: máscara el rostro y máscara la sonrisa. Plantado en su arisca soledad, espinoso y cortés a un tiempo" (Paz, 1995: 164) 
Las máscaras de Juan Rulfo. Revisión de dos cuentos de El llano en llamas

explotado y maltratado por el patrón, podría haber pasado tiempo acumulando un rencor inconfesable (el cual se intuye al describir Esteban el mal genio de la víctima) bajo su reservada máscara ${ }^{34}$ hasta estallar en un brote de violencia que acabaría con la vida de don Justo ${ }^{35}$. Portal enuncia las dos opciones que tiene el campesino frente a los abusos: actuar y violar la ley; no actuar y vivir en el rencor (Portal, 1990: 215). Pese a que no hubo una venganza como tal, el vaquero pudo haber decidido defenderse de los golpes eligiendo la primera opción. Si esta lectura es correcta y finalmente se encarcela al auténtico culpable del crimen ¿Significaría esto que se ha hecho justicia?

Aunque podría parecer que todo acaba como debe acabar, la información que poseemos como lectores, concretamente la que respecta a la brutalidad de don Justo, nos impide hablar de justicia. Resulta inútil preguntarse quién era la auténtica víctima, si el empleado que soporta el abuso del patrón o el patrón que sufre el arrebato del empleado. Al final "los muertos mandan" (Portal, 1990: 215), de modo que la balanza acaba inclinándose a favor del difunto y su presunto asesino es detenido. En este punto, cobran sentido las palabras de Rulfo (Sommers, 2003: 520) que defendían que "la justicia más justa es la mayor de las injusticias".

Los estallidos violentos suelen aparecer en los cuentos repentina y fugazmente, determinando la historia de forma implacable. La muerte puede aparecer como brutal sorpresa (el tiroteo de "Paso el Norte"), como espectáculo fríamente descrito (el ahorcamiento de Urbano Gómez en "Acuérdate") (Durán, 2003: 105) o como absurdo sinsentido (el asesinato de Remigio Torricos en "La cuesta de las Comadres"). La presencia de la muerte y la violencia en los cuentos está vinculada al ambiente que dejó tras de sí la Revolución y que Rulfo conoció en su infancia:

Siempre hubo apaciguamiento en los lugares donde yo estuve. Eran lugares tranquilos. Pero el hombre no lo era. El hombre traía una violencia retardada. Era de chispa

\footnotetext{
${ }^{34}$ Giménez Caro (2013) indica que Rulfo plasma la máscara de silencio violencia y resignación del campesino mexicano, no solamente en su obra literaria, sino también en sus fotografías, en las que se aprecian rostros desesperanzados y fantasmagóricos.

35 Ciertas técnicas narrativas parecen sugerir esta versión. Por un lado, se escribe que, en el momento de la pelea, don Justo gritó a su subordinado cosas "de las que él nunca conoció su alcance", sugiriendo que los gritos podrían haber provocado una reacción inesperada en el otro. Por otro, en el siguiente fragmento los puntos suspensivos parecen sugerir que estamos ante una elipsis, ante una omisión de información: "El viejo Esteban se levantó ya alto el sol (...) No se supo cómo abrió la puerta y se echó a la calle... No se supo cómo llegó a su casa, llevando los ojos cerrados dejando aquel reguero de sangre por todo el camino" (Rulfo, 1988: 74)
} 
Gracia TEROL Plá

retardada. Era un hombre que podía surgirle la violencia en cualquier instante. Y es que traían todavía los resabios de la revolución (...) Les había gustado el asalto, la violación, la violencia... (Soler Serrano, 1977: 00:15:50)

La violencia se desliza por las páginas de El llano en llamas, al igual que lo hace el profundo vacío que supone la muerte. Esta ya no constituye un concepto trascendental, sino el reflejo de lo caótico de la vida ${ }^{36}$ o, en palabras del autor, "una cosa atávica", "una cosa ilógica" (citado en Blanco Aguinaga, 1988: 15). Tal vez por ello Rulfo prefiera un enfoque objetivo que le lleva a no juzgar o posicionarse ${ }^{37}$ y nosotros no podamos hablar de desenlaces justos o injustos. Si, como decía Octavio Paz (1995: 189) "cada vida, encuentra en la muerte, ya que no sentido o explicación, fin", la muerte en las historias de Rulfo podría entenderse, no como equilibrio o castigo, sino como proceso cotidiano, como simple sinsentido o como final a secas.

Al final, resulta absurdo tratar de diferenciar víctima de victimario en un universo literario en que ambos se confunden y en que ningún desenlace justo parece ser posible. Tras la explosión violenta, estos campesinos mexicanos vuelven a su estado original, estado en que "la inexistencia de la víctima hace más intolerable y total la infinita soledad del victimario" (Paz, 1995: 196-197).

\subsection{La pobreza, otra forma de violencia}

Frente al impreciso crimen de "En la madrugada", Juan Rulfo nos ofrece en "Es que somos muy pobres" una historia sin misterio alguno, en la que el título mismo ya presenta una síntesis de todo el cuento: una familia que sufre las consecuencias de la pobreza. Y es que, aunque la crecida del río sea el origen inmediato de todos los males, por encima de esta se encuentra la pobreza, la verdadera causante del estado familiar. Pensemos que la falta de la cebada y la ausencia de la vaca y el becerro suponen un enorme desastre precisamente debido a que los campesinos se hallan en condiciones miserables. Partiendo de las ideas anteriores, interpretamos el cuento como una escala ascendente de calamidades cuyo fundamento es la pobreza rural.

El comienzo del relato ("Aquí todo va de mal en peor", Rulfo, 1988: 55) anuncia este proceso en el que se van sucediendo desdichas y cada una resulta más grave que la anterior. En esta estructura influye el tema de la pérdida de la ilusión por parte del campesinado, tema que ya mencionamos al hablar sobre el

36 "Si nuestra muerte carece de sentido, tampoco lo tuvo nuestra vida" (Paz, 1995: 189)

37 "Rulfo no quiere idealizar sino mostrar al hombre como ser concreto que soporta las normas impuestas por otros” (Monsiváis, 2003: 191-192) 
Las máscaras de Juan Rulfo. Revisión de dos cuentos de El llano en llamas

fracaso de las promesas de la Revolución. Conforme avanza la narración se observa que, tras la aparición de cada infortunio, se produce un leve alivio, un breve momento esperanzador. Pero esta impresión de mejora resulta ser falsa y enseguida se da una nueva desgracia que empeora aún más la situación. Tras la muerte de la tía, cuando se diría que los personajes ya van superando el duelo, son sorprendidos por la lluvia y el daño a la cebada. Pese al sobresalto en plena noche, el narrador se apacigua relajado por el sonido del agua, para luego descubrir la peligrosa inundación. Una vez que se produce la riada, se introduce un apartado descriptivo que parece rebajar la gravedad de la escena, pero que es seguido por la revelación de la muerte de la vaca.

Cada gran fatalidad aparece precedida de un instante aparentemente esperanzador que invita al lector a confiarse y que después se esfuma dejando paso a una dura realidad en la que los milagros o finales felices no tienen cabida. Aunque Rulfo nos cuenta una historia de tristeza y penurias, logra mantener el tono objetivo y desprovisto de patetismo. Creemos que esto, en parte, se debe a esos instantes de alivio que el autor intercala y que ayudan a manejar la tensión narrativa, aligerándola y recargándola en el punto justo, en un juego constante que combina ilusión y pérdida de esta. Igualmente, son estos momentos los que apoyan la idea de Durán (2003: 98) sobre la ausencia de naturaleza "trágica" en los personajes de Juan Rulfo. Según este autor, a diferencia del héroe trágico que se enfrenta a una situación a pesar de saber que no saldrá victorioso, los personajes de Rulfo no parecen ser conscientes de los infortunios que se ciernen sobre ellos. Esta falta de consciencia se traduce en los breves instantes esperanzadores que hemos destacado.

Se ha afirmado que "Macario" y "Es que somos muy pobres" son los únicos cuentos que no presentan asesinatos ni destacadas escenas de violencia. No obstante, en este último la muerte tiene un papel principal, ya que todo comienza con la muerte de la tía y se complica con la de la vaca. Es innegable que en esta historia el campesino vuelve a salir perjudicado. Recordando las facetas de la ley a las que se veía sometido el campesinado, la derrota esta vez sería causada por la ley del medio hostil que le rodea. La versión del México rural que Rulfo nos ofrece es dura y peligrosa. Mas, frente a esto, los personajes escogen la segunda opción que proponía Portal y no reaccionan ante los males reflejando la pasividad que se aprecia en el siguiente fragmento: "El aguacero llegó de repente (...) lo único que pudimos hacer, todos los de mi casa, fue estarnos arrimados debajo del tejaván, viendo cómo el agua fría que caía del cielo quemaba aquella cebada..." (Rulfo, 1988: 55).

Explica Blanco Aguinaga (1988: 29) que "no es que no les haya ocurrido nada grave. Es que lo que les ha pasado es una llaga más aceptada sordamente 


\section{Gracia Terol Plá}

en el camino hacia la muerte". Los campesinos, curtidos en penurias, aceptan con resignación el nuevo peldaño en la escala de desgracias, asimilándolo como algo cotidiano e inevitable. Por nuestra parte, creemos que, además del pesimismo y la costumbre de padecer la suerte adversa, es la pobreza lo que paraliza a los personajes, pobreza que es, después de todo, una forma más de violencia ${ }^{38}$. La pobreza hace que los personajes no puedan satisfacer sus necesidades y pierdan el control sobre su vida. Ante el ambiente amenazador, el campesino, carente de medios, no es capaz de defenderse ni de defender sus intereses. La falta de recursos le impide actuar, de modo que, cuando la cosecha de cebada se arruina, no puede hacer otra cosa más que contemplar el desastre.

A lo largo del relato, las desgracias van a más. Se crea un paralelismo entre las desdichas y el agua, de forma que a medida que aumenta la gravedad de los sucesos, aumenta también el nivel del río. Todo ello conduce a un final abierto en el que se deja sin aclarar una última cuestión: si el becerro ha muerto dejando a Tacha sin capital alguno. En nuestro caso, nos decantamos por la versión más pesimista, en la que el animal no sobrevive, por varios motivos. El primero de ellos tiene relación con la escala de desgracias y el tema de la pérdida de la ilusión. Si se interpreta el deseo (expresado reiteradamente por el narrador) de que el animal viva como uno de esos instantes esperanzadores que se anteponen a la siguiente tragedia, la estructura del cuento lleva a pensar que el deseo por recuperar al animal resultará vano y llevará a un final desolador. El segundo se basa en que tanto el desarrollo del cuento, como la reacción de los personajes (Tacha llora desconsolada) y la crecida del río (que sigue aumentando al terminar el relato) apuntan a un desenlace negativo que el lector solo puede intuir.

Pese a todo, el autor decide dejar el final abierto, quizás para sugerir que la escala de desgracias no ha finalizado, que no se detendrá al igual que no lo hace la riada. La serie de desdichas seguirá su curso y crecerá como lo hace el río, el cual no para de aumentar, y como lo hace Tacha ${ }^{39}$, cuyo desarrollo corporal incipiente anuncia que todo aún puede ir a peor.

38 Conviene recurrir al concepto de "violencia estructural" acuñado por Galtung, el cual hace referencia a una forma de violencia indirecta derivada de un conjunto de estructuras que incide negativamente en las oportunidades de supervivencia, bienestar y libertad de las personas (La Parra y Tortosa, 2003)

39 Mansour (2003: 293) ofrece otra interpretación en la que el río simboliza la maldad. De este modo, cuando se dice que parece que el río se ha metido dentro de Tacha se hace referencia a que el personaje acabará mal como las hermanas. Por su parte, Giménez Caro (2013: 226-227) ve en el agua un símbolo de la desgracia que aplasta el porvenir de Tacha. 
Las máscaras de Juan Rulfo. Revisión de dos cuentos de El llano en llamas

\subsection{La figura de la mujer y su máscara impenetrable}

Hasta ahora se han estudiado las diferentes manifestaciones de la violencia en los cuentos, distinguiendo la violencia retardada de estallido bestial y sorprendente de la violencia disimulada que oprime y paraliza bajo la forma de la pobreza. A continuación, abordamos un aspecto que las dos historias tienen en común: la manera de representar a la mujer. En otros relatos se identifican distintos tipos de personajes femeninos: la imagen de la esposa leal o desleal ("Luvina", "Paso del Norte"), la figura de la eterna solterona ("Anacleto Morones"), el símbolo de la madre o protectora ("La herencia de Matilde Arcángel", "Macario"), la mujer forzada ("El llano en llamas")... En este caso, decidimos escoger los dos cuentos que venimos estudiando porque nos permitían tratar ciertas cuestiones que rodean a la campesina mexicana en el universo rulfiano, como el matrimonio, la honra, la pasividad o el silencio.

"En un mundo hecho a la imagen de los hombres, la mujer es sólo un reflejo de la voluntad y querer masculinos (...) Su respuesta no es instintiva ni personal, sino conforme a un modelo genérico" (Paz, 1995: 171). Como se refleja en esta cita de Octavio Paz sobre la mujer mexicana, El llano en llamas suele mostrar a la campesina mexicana como ser pasivo que depende de la voluntad y la suerte del hombre que la mantiene. El matrimonio constituye el principal método de subsistencia de estos personajes femeninos, de forma que cuando este deja de funcionar, la mujer suele buscar otro hombre con el que emparejarse ${ }^{40}$. Este comportamiento se justifica, en muchos casos, debido a que los personajes no cuentan con una opción mejor ya que, como señala Estrada Cárdenas (2005: 40-45), en este universo literario mientras que la sumisión femenina es aceptada socialmente, la libertad es percibida como transgresión.

En los relatos observamos que la mujer que termina soltera es víctima de los engaños de hombres que se aprovechan de su situación y es además repudiada y rechazada por una sociedad que juzga sus actos y la percibe con asco y sospecha ${ }^{41}$. Pero deducimos algo más relevante. La solterona, a pesar de su estado, sigue dependiendo de una figura masculina que la mantenga y proteja, figura que, a menudo, coincide con el padre ${ }^{42}$. Por tanto, la campesina sin

${ }^{40}$ En "El llano en llamas" la mujer forzada termina formando una familia con su agresor como medio para salir adelante. Y en "Paso del Norte" cuando el marido abandona a su familia para intentar cruzar la frontera, la esposa se fuga con otro para subsistir.

${ }^{41}$ Algo así les sucede a las solteronas de "Anacleto Morones" que reciben el engaño del timador Anacleto y la burla y el rechazo de Lucas Lucatero y que, además, no pueden quedarse a pasar la noche en la casa porque serían juzgadas por la opinión pública.

42 Esta figura masculina en "Anacleto Morones" la encarnarían los padres de las viejas, los cuales son nombrados en el relato: "Diez mujeres, sentadas en hilera, con sus negros vestidos puercos 


\section{Gracia Terol Plá}

recursos, incapaz de depender de la casa paterna, solo tendrá dos alternativas: el matrimonio o la prostitución.

Respecto a la figura de la mujer en los cuentos analizados, destacaríamos tres cuestiones. La primera es que la mujer sin recursos tiene dos únicas salidas: conservar la honra y ser aceptada por la sociedad o perderla y ser repudiada (Portal, 1984: 162-165). "Es que somos muy pobres" gira en torno a esa idea, pues si Tacha no puede casarse tendrá que meterse a "piruja". Este caso también se da en "En la madrugada" en lo referente a la relación incestuosa de don Justo y su sobrina. El patrón llega a considerar el matrimonio con la niña, pero lo descarta rápidamente, consciente de que el cura no accederá. La vía matrimonial en este caso es imposible también debido a que la sociedad no aprobará el incesto y a que ya se ha malogrado la honra de Margarita. Sin honra ni probabilidades de casamiento, la única alternativa es la prostitución, hecho que se anuncia en los insultos de la madre que llama "prostituta" a la niña.

La mujer que se prostituye es apartada (primero de la casa paterna y después de la sociedad) bajo el pretexto de que el mal se ha adueñado de ella. Por eso, las dos hermanas de Tacha son consideradas malas y relacionadas con un castigo divino. El personaje de la campesina mexicana se encuentra ante un conflicto entre el querer y el deber, ya que "si satisface sus deseos sexuales será repudiada, pero si cumple lo que se espera de ella será aceptada" (Estrada Cárdenas, 2005: 75). Asimismo, el matrimonio incluye aspectos económicos a los que la mujer en estos cuentos debe hacer frente. Además de conservar su virginidad, se le exige algún tipo de bien que utilizar como dote para que el enlace sea efectivo, para que alguien "se haga el ánimo de casarse con ella" (Rulfo, 1988: 58). El matrimonio simboliza la salvación de la honra, que es también salvación social, y la mujer debe pagar un precio por dicha salvación. Esta circunstancia complica más la situación de la campesina sin recursos, pues solo tiene dos opciones y una de las dos, a menudo, no se la puede permitir. Esto se ve en "Es que somos muy pobres", donde la muerte de la vaca significa la ausencia de recursos, lo que a su vez implica quedarse sin opciones (Rulfo, 1988: 57-58):

La apuración que tienen en mi casa es lo que pueda suceder el día de mañana, ahora que mi hermana Tacha se quedó sin nada. Porque mi papá con muchos trabajos había conseguido a la Serpentina, desde que era una vaquilla, para dársela a mi hermana, con el fin de que ella

de tierra. Las hijas de Ponciano, de Emiliano, de Crescenciano, de Toribio el de la taberna y de Anastasio el peluquero. ¡Viejas carambas! Ni una siquiera pasadera” (Rulfo, 1988: 169). 
Las máscaras de Juan Rulfo. Revisión de dos cuentos de El llano en llamas

tuviera un capitalito y no se fuera a ir de piruja como lo hicieron mis otras dos hermanas, las más grandes. Según mi papá, ellas se habían echado a perder porque éramos muy pobres en mi casa y ellas muy retobadas.

La segunda cuestión que destacar en los cuentos es que la mujer es considerada la única responsable de su destino, mientras que el hombre tiende a librarse de las consecuencias de muchos de sus actos. Esto se aprecia en la preocupación del padre de Tacha que observa cómo los pechos de la niña crecen para atraer la atención de los hombres y presiente que la hija mostrará la misma desvergüenza que sus hermanas y "terminará mal" (Rulfo, 1988: 59). Escribe Paz que la mujer mexicana ha sido tratada como un ídolo "dueña de fuerzas magnéticas, cuya eficacia y poder crecen a medida que el foco emisor es más pasivo y secreto. Analogía cósmica: la mujer no busca, atrae" (Paz, 1995: 173). Según este planteamiento, la mujer atrae todo lo que le pasa y es, por tanto, culpable de ello. De ahí que Tacha aparezca como la responsable de desarrollarse y atraer a los hombres a pesar de que no poder hacer nada por evitarlo.

La misma explicación se aplica al incesto de "En la madrugada" pues, pese a que la hermana coincide con don Justo en la misma escena, esta se dirige en todo momento a la sobrina para preguntar qué ha sucedido. La mujer terminará insultando y acusando a su propia hija, sin siquiera dirigir la palabra al patrón (auténtico causante del incesto) por considerar que es la niña la culpable de no cuidar su honra como debiera. En definitiva, la mujer es la encargada de asegurarse un casamiento guardando su virginidad y acumulando ahorros que sirvan de dote. Ante imprevistos o injusticias que arruinen uno de estos dos requisitos, ella parece ser la única responsable de su suerte.

La tercera cuestión resalta el hecho de que la mujer en ambos cuentos está relegada al silencio y a la inacción. Si ya vimos cómo en las historias el campesino mexicano, ante las desgracias, oculta sus reacciones tras una máscara, en la campesina la tendencia se agudiza. Paz ha llegado a hablar de la "sufrida mujer mexicana" percibida como ídolo que "se transforma en víctima, pero en víctima endurecida e insensible al sufrimiento (...) Gracias al sufrimiento y a su capacidad para resistirlo sin protesta, la mujer trasciende su condición y adquiere los mismos atributos del hombre" (Paz, 1995: 174). A pesar de que en los relatos se aprecia la condición de víctima endurecida cuando la mujer resiste los infortunios sin mostrar debilidad, creemos que el mutismo y la inmovilidad son atributos impuestos que manifiesta y que la diferencian del hombre.

"En la madrugada" nos muestra a dos mujeres, una de ellas la hermana de 


\section{Gracia Terol Plá}

don Justo, "tullida desde hacía dos años, inmóvil, con su cuerpo hecho de trapo; pero siempre despierta. Solamente tenía un rato de sueño, al amanecer; entonces se dormía como si se entregara a la muerte" (Rulfo, 1988: 73). Podríamos preguntarnos a qué se debe la parálisis del personaje y conjeturar si esta condición posee un significado concreto dentro del relato. Quizás esta figura femenina inmóvil y atormentada sea símbolo de la inacción de la campesina, de su pasividad y de la posición marginal en la que queda apartada. La hermana, permanentemente despierta, es consciente de lo que sucede en su propia casa pero no puede hacer nada por evitarlo. Impotente, su única acción consistirá en acusar a la propia hija. Otra posibilidad es que la parálisis sea consecuencia de las tendencias incestuosas y la brutalidad de don Justo, quien, antes de descargarse con la sobrina, lo habría hecho con la hermana. Sin embargo, aunque la interpretación es coherente con el resto de la historia, reconocemos que es mucho suponer y que no hay auténticas pruebas en el cuento que apoyen nuestra lectura.

A lo largo del relato, la sobrina permanece en silencio. Pese a que es víctima de abusos e insultos y pese a que es precisamente este personaje quien descubre el cuerpo, en ningún momento sabemos qué piensa o siente. En un cuento en el que se ofrecen varias perspectivas del mismo hecho, este personaje permanece mudo. Por un lado, esto puede deberse a que, lógicamente, el asunto central del cuento sea la oscura muerte del patrón y sus protagonistas, en lugar de la situación de la sobrina. Por otro, podría suponer además una disimulada estrategia para caracterizar a la figura de la campesina como se ha venido señalando.

En "Es que somos muy pobres" el silencio se adueña de Tacha, hecho peculiar puesto que, a su vez, es el personaje primordial en torno al que gira el argumento. El narrador transmite la preocupación y los temores de los padres ante la pérdida de la vaca, pero sin reflejar nunca lo que pasa por la mente de la hermana. Tacha, centro del cuento sobre cuya suerte todos los personajes tienen algo que decir, no tiene voz. Tampoco la tienen las dos hermanas mayores dado que sobre ellas lo único que el lector averigua (eran malas, retobadas, rezongonas...) es información condicionada por la mentalidad familiar y por la mala reputación de la mujer que no guarda su honra. Si otros motivos (la pobreza, la falta de futuro) impulsaron a las hermanas a "andar con hombres de lo peor" (Rulfo, 1988: 58), como lectores, nunca lo sabremos. Ni sabremos, aunque se pueda intuir, qué siente Tacha frente al río ya que, llamativamente, el narrador que ha logrado empatizar con la vaca desaparecida poniéndose en su lugar e imaginando el sufrimiento del animal, se muestra incapaz de hacer lo mismo con la hermana. Más que dar voz a sus 
Las máscaras de Juan Rulfo. Revisión de dos cuentos de El llano en llamas

pensamientos, el narrador describe superficialmente la escena y abraza a Tacha en un intento torpe de consolarla.

Las campesinas de los cuentos son relegadas al silencio, tal vez por su condición marginal como ídolos o enigmas incomprensibles o porque, como explica Paz (1995: 174): "Pero ¿cómo vamos a consentir que ellas se expresen si toda nuestra vida tiende a paralizarse en una máscara que oculte nuestra intimidad?". Si la máscara del mexicano era oscura y hermética, la de la mujer rulfiana es totalmente impenetrable y la convierte en algo extraño y ajeno condenándola al aislamiento y la incomprensión.

\section{Conclusiones}

Mediante la comparación de las estructuras y características narrativas de los dos cuentos fue posible comprobar las particularidades que los diferencian. Queda patente que El llano en llamas, gracias a la variedad de cuentos que contiene, refleja la diversidad de técnicas narrativas que maneja Juan Rulfo.

Después del apartado analítico, ofrecimos una interpretación de los cuentos centrada en temas concretos. A través de la lectura de las dos historias, se estudian las distintas caras de la violencia que dejan al campesino impotente (violencia ejercida por una autoridad y por el medio o encarnada en la pobreza), las posibles reacciones del mexicano (estallar o aguatar pasivamente), las formas de presentar a la muerte (como suceso inesperado y accidental, trágico y fatal, trivial y cotidiano...) y la fuerte presencia que esta tiene en el universo rulfiano y en el mundo mexicano en general.

Además, destaca el tratamiento de la figura de la mujer en su obra y cómo esta aparece a menudo aislada, silenciada e inmovilizada; determinada por sus bienes y el estado de su honra; atrapada entre dos opciones que la llevan a depender, invariablemente, de un hombre. Se podría decir que el campesino mexicano, acosado por distintas formas de violencia y muerte que no puede evitar, decide encerrarse tras una máscara de reserva y silencio. Mientras que la mujer, acosada por los mismos males (y por otras exigencias exclusivas de su sexo), sufre una máscara de impotencia y sumisión que, a menudo, le viene impuesta por otros.

Conviene aclarar que, aunque Rulfo trata temas universales en su obra, en este caso nos centramos sobre todo en la relación de los temas que expone con la mentalidad mexicana y con el mundo rural de la posrevolución. Dada la riqueza de su obra, otras lecturas de los cuentos serían posibles. Sin embargo, por falta de espacio, nos ceñimos a una única perspectiva. Concluimos que Juan Rulfo tenía un amplio registro y gran cantidad de recursos de los que, seguramente, solo una parte quedaron reflejados en Pedro Páramo. El resto, las 


\section{Gracia Terol Plá}

posibles estructuras, estrategias y combinaciones de narradores que pudo crear están diseminadas por sus cuentos y son prueba de su talento y gran versatilidad como escritor.

\section{Referencias bibliográficas}

Blanco Aguinaga, Carlos, "Introducción". En: El llano en llamas, 1988, 1132.

Blanco Aguinaga, Carlos, "Realidad y estilo de Juan Rulfo". En: La ficción de la memoria: Juan Rulfo ante la crítica, 2003, 19-44.

DE LA FUENTE, José Luis, "Juan Rulfo: la narración desde la periferia". En: Castilla: Estudios de literatura, 21, 1996, 85-104.

DoÑÁN, Juan José, "El milagro Juan Rulfo". En: La ficción de la memoria: Juan Rulfo ante la crítica, 2003, 364-370.

DURÁN, Manuel, "Juan Rulfo, cuentista: la verdad casi sospechosa". En: La ficción de la memoria: Juan Rulfo ante la crítica, 2003, 89-121.

Estrada CÁRDENAS, Alba Sovietina, Estructura y discurso de género en Pedro Páramo de Juan Rulfo. México: Eón, 2005.

Fuentes, Carlos, El espejo enterrado. México D. F.: Fondo de Cultura Económica, 1992.

FUENTES, Carlos, "Juan Rulfo: el tiempo del mito". En: La ficción de la memoria: Juan Rulfo ante la crítica, 2003, 252-272.

GARRIDO, Felipe, "La sonrisa de Juan Rulfo". En: La ficción de la memoria: Juan Rulfo ante la crítica, 2003, 242-252.

GIMÉNEZ CARO, Isabel, "Las imágenes de los vivos y las imágenes de los muertos: Del Páramo de Rulfo al desierto de Bolaño". En: Diálogos culturales en la literatura iberoamericana, (ed.) Reverte Bernal, Concepción, 2013, $1224-$ 1233.

GÓMEZ LÓPEZ-QUiÑONES, Loreto, "El silencio como estrategia en la obra de Rulfo". En: Analecta Malacitana, 35, 2013, 19-92.

González Boixo, José Carlos, "Estrategias de lo insólito en Pedro Páramo". En: La (ir)realidad imaginada: aproximaciones a lo insólito en la ficción, (coords.) Ortiz, Inés y Díez, Rosa María, 2015, 111-122.

GONZÁLEZ BOIXO, José Carlos, Claves narrativas de Juan Rulfo. León: Universidad de León, 1983.

GonZÁlez VÁZQueZ, Carmen, Teatro latino. Léxico, dramaturgia, escenografía, Madrid: Diccionario Akal, 2014.

GORDON, Samuel, "Juan Rulfo: una conversación hecha de muchas (diálogos entre textos, pre-textos y para-textos)". En: La ficción de la memoria: Juan Rulfo ante la crítica, 2003, 342-354. 
HARSS, Luis, "Juan Rulfo o la pena sin nombre". En: La ficción de la memoria: Juan Rulfo ante la crítica, 2003, 61-89.

LA PARRA-CASADO, Daniel y TORTOSA, José María, "Violencia estructural: una ilustración del concepto". En: Documentación social, 131, 2003, 57-72.

MANSOUR, Mónica, "El discurso de la memoria". En: La ficción de la memoria: Juan Rulfo ante la crítica, 2003, 283-300.

MONSIVÁIS, Carlos, "Sí, tampoco los muertos retoñan. Desgraciadamente". En: La ficción de la memoria: Juan Rulfo ante la crítica, 2003, 187-203.

PAZ, Octavio, El laberinto de la soledad. Madrid: Cátedra, 1995.

POOT HERRERA, Sara, "Narradores asesinos en El llano en llamas". En: La ficción de la memoria: Juan Rulfo ante la crítica, 2003, 398-409.

PORTAL, Marta, Procesos comunicativos en la narrativa de Juan Rulfo. Madrid: Editorial de la Universidad Complutense de Madrid, 1984.

PORTAL, Marta, Rulfo: dinámica de la violencia. Madrid: Cultura Hispánica, 1990.

ROA BASTOS, Augusto, "Los trasterrados de Comala". En: La ficción de la memoria: Juan Rulfo ante la crítica, 2003, 203-215.

RODRÍGUEZ-AlCALÁ, Hugo, "Un cuento entre dos luces: En la madrugada, de Juan Rulfo". En: Actas del Segundo Congreso Internacional de Hispanistas (coords.) Polussen, Norbert y Sánchez Romerato, Jaime, 1967, 499-512.

RofFé, Reina, Juan Rulfo. Biografía no autorizada. Madrid: Fórcola, 2012.

RUFFINELLI, Jorge, "La leyenda de Rulfo: cómo se construye el escritor desde el momento en que deja de serlo". En: La ficción de la memoria: Juan Rulfo ante la crítica, 2003, 300-337.

Rulfo, Juan, El llano en llamas. Madrid: Cátedra, 1988.

Rulfo, Juan, Pedro Páramo. Madrid: Cátedra, 1984.

SOler Serrano, Joaquín, A fondo. Juan Rulfo. 1977. Disponible en línea en: http://www.rtve.es/alacarta/videos/a-fondo/juan-rulfo-fondo1977/980963/ [Fecha de consulta: 25 de junio de 2017]

SOMMERS, Joseph, "Los muertos no tienen tiempo no espacio (un diálogo con Juan Rulfo)". En: La ficción de la memoria: Juan Rulfo ante la crítica, 2003, $517-$ 522.

Valles Calatrava José y Álamo felices, Francisco, Fundamentos de Semiótica Narrativa. Almería: Servicio de Publicaciones de la Universidad de Almería, 2000.

VILA-MATAS, Enrique, Bartleby y compañia. Barcelona: Anagrama, 2000.

Villoro, Juan, "Lección de arena. Pedro Páramo". 2009. Disponible en línea en: http://www.cervantesvirtual.com/obra/leccion-de-arena-pedro-paramo--0/ [Fecha de consulta: 25 de junio de 2017] 